\title{
Exploring New Research Frontiers in Offshoring Knowledge and Service Processes
}

\author{
William Youngdahl \\ Thunderbird School of Global Management \\ Kannan Ramaswamy \\ Thunderbird School of Global Management \\ Rohit Verma \\ University of Utah
}

This paper provides an introduction to a special issue on the offshoring of service and knowledge work. Brief descriptions are provided for 13 papers that fall into three categories including strategic and organizational issues, global and knowledge supply chain issues, and tactical issues. The intent of this special issue was to provide a venue for presenting numerous perspectives on the operational and cross-disciplinary challenges and opportunities in the area of service and knowledge offshoring.

\section{Introduction}

A Forrester report, in 2002, suggested that over 3.3 million jobs worth US \$136 billion would migrate from the U.S. to low-wage countries between 2000 and 2015 (McCarthy, 2002). Similar predictions have been made about much of the developed world which is home to a dominant majority of the world's multinationals. While the first wave of outsourcing and offshoring involved labor-intensive manufacturing assembly positions, the current wave includes service and knowledge-worker positions. This new wave has been enabled in part by the widespread availability of a reliable information infrastructure coupled with advances in telecommunications that make distributed control of operations feasible in real-time.

This meteoric rise of the incidence of offshoring knowledge and service work has unfortunately not been paralleled by insightful research that can shed light on the antecedents, processes and consequences associated with these industry trends. For example, much of the intellectual debate around offshoring has been limited to direct examination of costs and benefits such as labor rates, location advantages associated with regulation, and tax incentives. However, it has become clear that this phenomenon continues to be driven by factors that transcend mere cost considerations alone. Issues such as the ability of an organization to manage its offshore providers, its skill in leveraging the supply chain both in terms of process control as well as scheduling are gaining wider importance. Thus, from a pragmatic standpoint, our aim must be to deal with the realities of outsourcing and offshoring rather than to debate the impact offshoring may have on domestic employment (Harrison and McMillan, 2006). 


\section{The Context of the Special Issue}

In establishing the broader perspective for this Special issue on Offshoring of Knowledge and Service Work, we provide a brief survey of the domain and the critical evolutionary path that the trend has traversed thus far. This discussion serves as a useful framework within which the contributions of the individual research contributions showcased in this issue can be better understood.

Broadly defined, service and knowledge offshoring can be described as the process of moving service and knowledge work from a home country to an offshore location. The common approaches to offshoring include captive (company-owned) processing centers, third party providers (outsourcing), and joint ventures (build, operate, and transfer).

When organizations desire to maintain complete control over their offshore operations, they pursue a captive offshoring strategy. Consider the case of American Express. American Express Travel Related Services (TRS) had more than 46 transaction processing sites each with 20-40 employees. These sites were distributed across numerous regions including North America, Latin America, Europe, Middle East, and Africa (EMEA) and Asia-Pacific and Australia (APA). In the mid-1990s, the company decided to consolidate these various transaction centers into three shared services centers: one in Phoenix, Arizona, to serve the Americas; one in Brighton, UK, to serve Europe; and one in Gurgaon, India, to serve Japan and APA (Robinson and Kalakota, 2004).

American Express' decision to pursue a captive offshoring strategy has provided opportunities to reduce overall costs, largely as a result of the significantly reduced labor wages in India, and shift workload among the regional service centers to provide capacity flexibility and serve global customers 24 hours per day. They are also able to establish global best practices across the regional service centers. Thus, the approach has the distinction of being able to not only leverage lower comparative costs but also leverage learning and knowledge from various nodes within the network to elevate the overall capabilities of the organization.

When an organization's management team decides to outsource service and knowledge work to a third-party provider, overall cost savings usually figures prominently in the decision making process. This drive to reduce costs was largely responsible for the emergence of the business process outsourcing (BPO) industry made up initially of offshore providers that performed basic transaction processing and operated call centers (Clott, 2004). Working with BPO providers requires an organization to transfer segments of its operations, and associated best practices, to third-party suppliers. Issues of cross-organizational control, contracting, and capacity and flexibility assurances dominate the agendas of operations managers contemplating offshore outsourcing. These issues do not differ significantly from manufacturing outsourcing decisions for back-office transaction processing. However, for operations such as call centers involving direct communication with consumers, managing cultural differences and service quality dimensions such as empathy become central challenges. 
Since the early days of BPO, the industry has evolved such that several BPO providers now provide transformation outsourcing. By leveraging the deep experience of third-party offshore service providers such as Wipro, companies can pursue a path of not only reducing overall costs but also achieving transformations in their service and knowledge processes (Linder, 2004). Engardio et al. (2006) aptly describe the transformational BPO process as one in which Genpact, Accenture, IBM Services, or another BPO provider dissects the workflow of an entire function such as human resources, finance or IT. The BPO team then redesigns and administers new processes. The BPO provider as a virtual subsidiary further distributes the work among its own sites spread across the world. Some offshore service providers have better abilities to improve service and knowledge processes than can be found inside many organizations.

The build-operation-transfer (BOT) model fall somewhere between offshore outsourcing and captive offshoring. This option provides an opportunity to leverage the unique talent of a third-party provider to establish offshore operations and then transfer the operations to full control of the customer company after a specified time frame. For example, Tensilica a private, venture-capital financed semiconductor intellectual property company headquartered in Santa Clara, CA, decided to expand its core engineering team by establishing a team of engineers in India. It formed a BOT offshoring arrangement with elnfochips, located in Ahmedabad, India. During the "build and operate" phase, Tensilica paid elnfochips a fixed per-month fee based on the number of engineers. The transfer occurred, at Tensilica's discretion, during the predetermined 18-24 month timeframe at a pre-negotiated transfer fee (Dixit, 2007). The BOT approach has become de rigueur in many industries where distinctive competence is built around unique knowledge bases such as design, engineering, and chemical technology. A large number of companies in settings such as drugs and pharmaceuticals, advanced automotive and aerospace engineering design, have embraced the BOT route to establishing offshore operations. Building on their success some of the really large-scale companies (e.g., Dayton Hudson's Target, Pearson Publishing, British Airways, and Lufthansa) have also chosen to adopt a similar approach even for routine transactions processing. As is evident, the BOT approach raises a different set of issues compared to transacting offshore processes through an armslength arrangement with an independent BPO provider. The focus shifts from mere costbenefit analyses to a need for a more robust understanding of issues related to talent procurement, development and management.

Taken together, the preceding synopsis of some of the key gateways into the offshoring world demonstrates the diversity of strategic, organizational, and operational issues that emerge within this realm. In spurring research that would help both practitioners and academics comprehend this diversity of related topics within the general domain of offshoring, the special issue was conceived. 


\section{The Special Issue}

The objective of this special issue on offshoring of service and knowledge work was to publish a set of papers to provide insights into the operational implications of the current trends in offshoring. The call for papers encouraged submissions that would address a broad range of issues ranging from strategic and organizational concerns to the management of global service and knowledge supply chains and more tactical issues such as the coordination of work. In each case, researchers were provided with broad sets of questions that could guide their thoughts in submitting work that would address service and knowledge offshoring from the broadest possible set of perspectives. We encouraged submissions that would apply different methodologies ranging from case studies to optimization approaches and different disciplinary, and ideally cross-disciplinary, perspectives.

\section{Strategic and Organizational Issues}

- What types of services and knowledge functions can be outsourced?

- Should we outsource or create corporate-owned offshore operations?

- What are the best locations for offshore operations?

- How will this change over time?

- How can we achieve performance breakthroughs through transformational outsourcing?

\section{Global Service and Knowledge Supply-Chain Issues}

- Can we really "follow the sun?"

- How do we best manage handoffs?

- How does culture influence the management of geographically distributed operations?

- How can we manage operations to minimize total cost of ownership from a supply-chain perspective?

- When using offshore service providers, will we encounter tradeoffs between operational efficiency and customer intimacy? If so, can such tradeoffs be eliminated or minimized?

\section{$\underline{\text { Tactical Issues }}$}

- What are the best practices for coordinating the work of global virtual teams that include offshore service providers?

- How can we maintain and improve the quality of offshore operations, especially when the service or knowledge work is outsourced to a third-party provider?

- Can we optimize global supply networks that include heavy service and knowledge component? If so, how can we make optimization approaches accessible to practicing managers? 
The contributions fall into the following three categories: strategic and organizational issues; global service and knowledge supply-chain issues; and tactical issues. These papers are described briefly in the following section to allow the opportunity for focused reading based on research interests.

\section{The Special Issue Contributions}

In total, 39 papers of high-quality were submitted to the special issue. After a rigorous double-blind review process, 13 papers were ultimately accepted for the special issue. The selection of 13 papers reflects our intent to share diverse perspectives that can be used to formulate individual research agendas for the topic of offshoring of service and knowledge work. At this very early stage in investigating a highly interdisciplinary area of inquiry, we quite simply preferred to cast a wide net versus the approach of driving toward a more restricted paradigm. We view this diversity of perspectives and methodologies as an opportunity for operations management researchers to embrace specific papers from perspectives that align with their own personal research agendas. Our hope is that this initial foray into service and knowledge offshoring will stimulate dialogue and further research. We thank all authors who submitted papers for this special issue on the offshoring of service and knowledge work.

Fitting the contributions into categories did not represent an easy task. Many of the papers spanned strategic, organizational, global knowledge and service supply chain, and tactical issues. The categorization of these papers represents a good-faith attempt to organize the contributions in a manner consistent with the original call for papers.

\section{Strategic and Organizational Issues}

An introductory paper, "The history of offshoring knowledge services," by Richard Metters and Rohit Verma, provides a brief overview of the antecedents of the current state of affairs in offshoring. The authors argue that a combination of US government neglect, foreign government activism, a culture change among businesspeople concerning service processes, technological advances, and cultural relationships among countries created the specific services offshoring configuration of today.

Next, Lisa Ellram, Wendy Tate, and Corey Billington present a paper entitled "Offshore outsourcing of professional services: A transaction cost economics perspective" in which they utilize a transaction cost economics framework to develop an understanding of how firms manage the costs and risks of offshore outsourcing of professional services. By examining perspectives from eight organizations through interviews with high-ranking executives, the authors provide the pragmatic conclusion that the fixed costs of establishing relationships in offshoring dominate the variable costs of day to day transactions. The paper provides guidelines for managing and controlling offshore outsourced services relationships. 
In their paper entitled "Invisible costs in offshoring services work," Anne Stringfellow, Mary Teagarden, and Winter Nie combine existing service operations theory with literature on communication and culture to present a new conceptual framework. This framework is organized around interaction intensity and interaction distance. The authors identify cost drivers and conclude with recommendations for controlling or attenuating invisible costs in the offshoring of service work.

Shiri Ghandi, D.K. Banwet, and Ravi Shankar apply interpretive structural modeling to examine changing emphases of specific elements in offshoring alliances in their paper entitled "Analysis of interactions among core, transaction and relationships specific investments: The case of offshoring." The authors present a study of how emphases change over time by examining complex relationships between investments in core, transaction and relationshipspecific assets. They conclude that the complex combination of investments helps offshoring clients attain evolving objectives in offshoring alliances.

Rich Metters, in his paper entitled "A typology of offshoring and outsourcing electronically transmitted services," presents a normative model for the appropriate role of offshoring. The strategic contingency model, viewed at the process level, leads to the conclusion that organizations with similar processes should come to different offshoring decisions based on several factors. Indeed, a proportion of service processes now being offshored are likely to remain in high-wage countries.

The final paper in this category, "Offshoring knowledge and service work: A conceptual model and research agenda," William Youngdahl and Kannan Ramaswamy present two complementary conceptual models and several propositions. The authors examine the role of customer contact and knowledge embeddedness to identify different types of offshore service centers. Several propositions provide opportunities for expanding research in the area of service offshoring. The authors conclude with a model that helps to describe strategic roles for offshore service centers as well as the evolution of these roles as environments and strategies change.

\section{Global Service and Knowledge Supply-Chain Issues}

Brian Fifarek, Francisco Veloso, and Cliff Davidson present and industry-based case study in their paper entitled "Offshoring technology innovation: A case study of rare Earth technology. The authors examine service and knowledge offshoring from the perspective of the impacts on innovation in the rare Earth elements industry. They argue that there has been a progressive offshoring of critical knowledge-based components of organizations active in rare Earth technology. Their research supports theories that suggest that offshoring elements of the system relevant for technology innovation may reduce the level of R\&D and productivity of innovation processes at the home location.

In their paper, "Effective strategies for internal outsourcing and offshoring of business services: An empirical investigation," O. Zeynep Aksin and Andrea Mansini present a conceptual 
model that challenges the notion of best practice and suggest that effectiveness of shared services projects depends on the degree of complementary between specific company needs and capabilities developed to address those needs. Their theoretical findings are validated empirically through a large sample study of European firms that recently undertook shared services initiatives.

In their paper entitled "Transformational offshore outsourcing: Empirical evidence from alliances in China," Yuan Li, Yi Liu, Mingfang Li and Haibin Wu provide an empirical examination of the relationship among the motive to acquire tacit knowledge from outsourcing partners, formal and social control mechanisms, and innovation outcomes among Sino foreign as well as local alliances. They present a theoretical model that incorporates knowledge management, social exchange, and alliance risk perspectives. Their study reveals that the motive to acquire an outsourcing partner's tacit knowledge and control mechanisms are significant predictors of both incremental and radical innovation outcomes.

Jeff Stratman, in his paper "Facilitating offshoring with enterprise technologies: Reducing operational friction in the governance and production of services," identifies challenges to the positive effects of offshoring of services. Competitive capability literature guides a discussion of how firms might acquire internal capabilities required to manage offshore service processes. The author presents several propositions reflecting the benefits of standardized transactional enterprise technologies in mitigating the challenges of offshore governance.

Karthik Balakrishnan, Usha Mohan, and Sridhar Seshadri, in their paper entitled "Outsourcing of frontend business processes: Quality, information, and customer contact," present a study that helps to explain the relatively recent phenomenon of offshoring frontend supply-chain processes. They use an analytical model to conclude that the ability of the supplier to forecast the task environment without bias might make an organization in different between offshore outsourcing and keeping front-end knowledge-based supply-chain processes in-house.

\section{$\underline{\text { Tactical Issues }}$}

In their paper entitled "Monitoring process quality in offshore outsourcing: A model and findings from multi-country survey," Ravi Aron, Subhajyoti Bandyopadhyay, Siddharth Jayanty, and Praveen Pathak present an investigation on how recent advances in IT and telecommunications have led to real-time monitoring of processes at offshore providers' sites by buyers located across the globe. Their game-theoretic model of the dynamics of the buyersupplier interaction enhances the diversity of methodological approaches shared in this special issue. Their model explains why offshore providers' processes that are complex and more prone to errors are actually monitored less by buyers. The authors also provide the results of a comprehensive, multi-year, multi-country survey to provide empirical support for the findings of the model. 
In their paper entitled "Is more IT offshoring better? An exploratory study of Western companies offshoring to Southeast Asia," Ajay Bhalla, ManMohan Sodhi and Byung-Gak Son explore the link between a company's performance and the extent of its offshoring of IT enabled services. Since no clear link was identified between company performance and the extent of offshoring, the authors call for further research to understand better when to offshore and what benefits can be expected from offshoring.

\section{Conclusion}

This special issue on the offshoring of services and knowledge work has provided an opportunity for researchers to explore offshoring from many disciplinary and interdisciplinary perspectives using approaches ranging from the development of conceptual models to more rigorous analytical and empirical modeling. It is our hope that this diverse set of contributions is viewed as a broad set of potential directions for conducting more research in the area of service and knowledge offshoring. In essence, the diversity suggests both opportunity for pursuing many directions and a challenge for us as operations management researchers to develop a more focused research agenda for better understanding how we might provide the greatest value to those engaged in the practice of service and knowledge offshoring.

The special issue guest editors would like to thank Robert Handfield for encouraging a special issue on the topic of service and knowledge offshoring and Kenneth Boyer and Morgan Swink, the new JOM Editors, for seeing this through to completion. We would also like to thank numerous anonymous reviewers for providing rigorous reviews that helped to improve the papers. Finally, we thank the authors for taking some risks to explore the relatively unchartered research domain of service and knowledge offshoring.

\section{Reference}

Clott, C.B., 2004. Perspectives on global outsourcing and the changing nature of work. Business and society Review 109 (2), 153-170.

Dixit, A., 2007. Build Operate Transfer: Tensilica's Experience in Offshoring Engineering to India. Sourcingmag.com. http://www.sourcingmag.com/content/c060320a.asp.

Engardio, P., Arndt, M., Foust, D., 2006. The future of outsourcing. Business Week 30 (January), 50-58.

Harrison, A.E., McMillan, M.S., 2006. Dispelling some myths about offshoring. Academy of Management Perspectives 20 (4), 6-22.

Linder, J.C., 2004. Transformational outsourcing. Sloan Management Review 2 (45), 52-58.

McCarthy, J., 2002. 3.3 m US Service Jobs to go Offshore. Forrester Report.

Robinson, M., Kalakota, R., 2004. Offshore Outsourcing: Business Models, ROI and Best Practices. Mivar Press. 